\title{
Comparative Effects of Scorpion Venom and Aqueous Basil (Ocimum basilicum) Leaves Extracts on Ccl4-induced Toxicity in Albino Rats
}

\author{
Muhammad MA Salman*, Naglaa RA Kasem and Nora HM Saleh
}

Department of Zoology, South Valley University, Qena, Egypt

\begin{abstract}
The present study aims to compare the therapeutic effects between to extract scorpion venom (bradykinin potentiating factor; BPF) and aqueous extract of Sweet basil (Ocimum basilicum) on $\mathrm{CCl}_{4}$-induced toxicity of liver and kidney in albino rats. Rats were divided into 8 groups. Group (1) was served as normal group; Group (2) was injected intraperitoneal (i.p.) once a week for 3 weeks with BPF at a dose $(1 \mu \mathrm{gm} / \mathrm{g})$. Group (3) was received orally O. basilicum extract, twice a week for 6 weeks at dose $(20 \mathrm{ml} / \mathrm{kg})$. Group 4 was treated with the same doses of BPF and $O$. basilicum. Group (5) was injected i.p. with $\mathrm{CCl}_{4}(1 \mathrm{ml} / \mathrm{kg}), 3$ times weekly, for 2 weeks and served as control group. Groups 6, 7 and 8 were injected i.p. with $\mathrm{CCl}_{4}$ then treated i.p. with BPF, orally with 0 . basilicum and BPF plus $O$. basilicum respectively. The results of the present study cleared that normal group (1) and groups (2, 3 and 4) showed no significant difference in all liver and kidney functions, besides antioxidant enzymes except creatinine and $\mathrm{GSH}$, were highly significant increase in group (4). $\mathrm{CCl}_{4}$ caused a highly significant decrease in serum albumin, uric acid, besides Catalase, GSH, SOD activities in liver tissue, while there are an elevation in serum AST, ALT, ALP, Y-GT, creatinine and Urea, besides MDA and NO levels in liver tissue. While, groups (6, 7 and 8$)$ revealed reverse effect in all parameters and recorded a remarkable improvement, comparing with normal group. It can be concluded that the treatment with the extract from the scorpion venom Buthus occitanus (BPF) is more effective than those of extract from the plant $\left(\mathrm{O}\right.$. basilicum) against the toxicity of liver and kidney-induced by $\mathrm{CCl}_{4}$ in albino rats. In addition, the hepato-ameliorating and antioxidant effects of two extracts were found to be better than those of extract of BPF or $O$. basilicum indepently.
\end{abstract}

Keywords: BPF; O. basilicum; Buthus occitanus; $\mathrm{CCl}_{4}$; Antioxidant; Albino rats

\section{Introduction}

Carbon tetrachloride ( $\left.\mathrm{CC}_{4}\right)$ is one of the aliphatic hydrocarbons (chlorinated hydrocarbons) that has wide spread uses in different industrial sectors as in production of chlorofluorocarbon refrigerants, foam-blowing agents, cleaning compounds, organic solvents industry $[1,2] . \mathrm{CC}_{4}$ is a highly toxic chemical agent $[3,4]$. It is considered as one of the environmental pollutants which mainly cause hepatotoxic effect. Also, $\mathrm{CCl}_{4}$ is considered as one of the most commonly used toxins in the experimental study of liver diseases and induction of hepatic cirrhosis [5,6]. liver necrosis and liver fibrosis [7]. $\mathrm{CC1}_{4}$ can induce the oxidative stress beside the inhibition of the activity of the antioxidant enzymes in renal tissue [8]. Oxidative stress has been shown to play a very crucial role in some diseases including liver disease. Free radical that generate inside the body is responsible for oxidative stress and antioxidant compounds that can scavenge free radicals have great potential in ameliorating these disease processes $[9,10]$. Various studies have demonstrated that carbon tetrachloride intoxication causes free radical generation in many tissues such as liver, kidney, heart, lung, testis, brain and blood [11-13]

Bradykinin potentiating factor (BPF) fractions have many physiological effects, Nassar et al. [14] isolated BPF1, BPF2 and BPF3 from the Egyptian scorpions, Buthus occitanus and Leiurus quinquestriatus as well as the Cobra; Naja haje respectively. These fractions considerably enhance urea and creatinine clearance. They elevate enzyme activities in different organs (especially liver and heart) and creatine kinase and alkaline phosphatase in blood $[15,16]$. Egyptian scorpion Buthus occitanus, contains a strong BPF that was proved to enhance pharmacological effect of bradykinin (BK) on guinea pig ileum [17]. Moreover, topical on burnt application of BPF on skin of guinea pigs accelerate the healing and stimulate kidney and liver functions [18].
Many natural and synthetic agents possessing antioxidative properties have been proposed to prevent and treat hepatopathies induced by oxidative stress [19]. There is increasing evidence of the hepatoprotective role of hydroxy and polyhydroxy organic compounds, particularly from vegetables, fruits and some herbs [20,21]. Sweet basil (O. basilicum) is a plant that belongs to the family Labiatae and is known as Holy Basil in English and Rehan in Egypt. It was employed traditionally as a folk remedy for a wide spectrum of aliments. Basil is known to have numerous pharmacological activities. Basil leave extracts have potent antioxidant, anti-aging, anticancer, antiviral, and antimicrobial properties [22,23].

The aim of this work was to highlight the reverse effect of BPF and O. basilicum against the toxicity of $\mathrm{CCl}_{4}$ on albino rats, and also to compare the curative effect of bradykinin potentiating factor on $\mathrm{CCl}_{4-}$ induced toxicity in albino rats with that of $O$. basilicum extract.

\section{Materials and Methods}

\section{Materials}

Animals: This experiment was carried out on 56 adult male albino rats weight about (250-280 g). The animals were obtained from the

*Corresponding author: Muhammad MA Salman, Faculty of Science, Department of Zoology, South Valley University, Qena, Egypt, Tel: +201159600729; E-mail: Salman2_2014@yahoo.com

Received August 25, 2016; Accepted September 19, 2016; Published September 27,2016

Citation: Salman MMA, Kasem NRA, Saleh NHM (2016) Comparative Effects of Scorpion Venom and Aqueous Basil (Ocimum basilicum) Leaves Extracts on Ccl4 induced Toxicity in Albino Rats. J Liver 5: 201 doi: 10.4172/2167-0889.1000201

Copyright: (c) 2016 Salman MMA, et al. This is an open-access article distributed under the terms of the Creative Commons Attribution License, which permits unrestricted use, distribution, and reproduction in any medium, provided the original author and source are credited. 
animal house of the Egyptian Organization for Biological products and vaccines Helwan, Cairo. Egypt. Rats were maintained in animal house of department of Zoology, Faculty of Science, South Valley University, Qena, Egypt. The rats were divided into eight groups housed in controlled suitable plastic cages with natural day and night periods and kept at room temperature and fed on balanced stable commercial diet for drinking tap water was provided ad libitum. Animals were examined daily for two weeks, before starting the experiment.

Carbon tetrachloride $\left(\mathrm{CCl}_{4}\right): \mathrm{CCl}_{4}$ is a colorless non-flammable liquid, of molecular weight 153. 84 was obtained from El-Nasr Pharmaceutical Chemical Company.

Bradykinin potentiating factor (BPF): Bradykinin and its related peptides are widely distributed in venomous animals, including scorpion. A peptide fraction isolated from the venom of the Egyptian scorpion Buthus occitanus was proved to have a bradykininpotentiating activity. Buthus occitanus contains a strong BPF that was proved to enhance pharmacological effect of BK on guinea pig ileum.

Ocimum basilicum (O. basilicum) known as Rehan in Arabic and sweet basil in English belongs to the Lamiaceae family. It is an Egyptian plant used as a folkloric remedy in Egyptian traditional medicine. In the current study, the leaves of this plant were used $[24,25]$.

Biochemical kits: All biochemical kits except ( $\gamma$-Glutamyltransferase " $\gamma$-GT", Glutamic-Pyruvic Transaminase "GPT", Glutamic-Oxaloacetic transaminase "GOT" and Creatinine) were brought from bio-diagnostic co. Giza. Egypt. $\gamma$-GT was brought from Spectrum co. Cairo. Egypt. While GPT and GOT were brought from Human company. And Creatinine was brought from Diamond Company.

\section{Methods}

Isolation of BPF: Firstly the crude venom was collected from scorpion, Buthus occitanus gathered from the Aswan area. The scorpions were milked in the physiology laboratory at the Faculty of Science in Qena, South Valley University with a specific device using electrical shocks ( 6 volts) at the articular membrane of the telson. The collected droplets were received into a clean dry glass container. The venom was lyophilized and freeze dried after which it was kept at $-10^{\circ} \mathrm{C}$ (in the dark) until it was used. The venom fraction (BPF) separated from Buthus occitanus was isolated, purified and detected according to the method of Ferreira et al. [25].

Preparation of Ocimum basilicum extract: Fresh leaves of $O$. basilicum were collected from a garden within the gardens of south valley university, Qena, Egypt. The leaves were rinsed with clean water to remove any foreign matter. Leaves were blended with distilled water. The mixture was strained, pressed and the mixture was filtrated using filter paper. The aqueous extract was used at a dose level of $20 \mathrm{ml} / \mathrm{kg} O$. basilicum [26].

\section{Experimental design}

The experimental animals were randomly assigned into 8 groups, 7 rats for each group.

Group 1: Rats were injected i.p. with $0.9 \%$ isotonic saline solution at $\operatorname{dos}(10 \mathrm{mg} / \mathrm{kg}$ b.wt $)$ and used as normal group.

Group 2: (BPF treated) rats were injected i.p. with BPF $(1 \mu \mathrm{gm} / 1 \mathrm{~g}$ b. wt.), once a week for 3 weeks.

Group 3: (O. basilicum treated) rats received oral doses of $O$. basilicum ( $20 \mathrm{ml} / \mathrm{kg}$ b. wt.) twice a week for 6 weeks.
Group 4: $(\mathrm{BPF}+\mathrm{O}$. basilicum) rats were treated i.p. with BPF (1 $\mu \mathrm{gm} / \mathrm{g}$ b.wt.) once a week for three weeks plus oral administration of O. basilicum $(20 \mathrm{ml} / \mathrm{kg}$ b. wt) twice a week for six weeks.

Group 5: Rats were injected i.p. with $\mathrm{CCl}_{4}(1 \mathrm{ml} / \mathrm{kg}), 3$ times weekly, for two weeks and served as control group.

Group 6: $\left(\mathrm{CCl}_{4}+\mathrm{BPF}\right)$ animals were injected i.p. with $\mathrm{CCl}_{4}(1 \mathrm{ml} / \mathrm{kg}$ b.wt.), 3 times weekly for 2 weeks, following with i.p. injection of BPF ( $1 \mu \mathrm{gm} / 1 \mathrm{~g}$ body weight) once a week for 3 weeks.

Group 7: $\left(\mathrm{CCl}_{4}+O\right.$. basilicum $)$ rats were injected i.p. with $\mathrm{CCl}_{4}$ ( $1 \mathrm{ml} / \mathrm{kg}$ per b. wt.), 3 times weekly for 2 weeks, following with oral administration of $O$. basilicum ( $20 \mathrm{ml} / \mathrm{kg} \mathrm{b}$. wt.) twice a week for 6 weeks.

Group 8: $\left(\mathrm{CCl}_{4}+\mathrm{BPF}+\mathrm{O}\right.$. basilicum $)$ rats were injected i.p. with $\mathrm{CCl}_{4}$ ( $1 \mathrm{ml} / \mathrm{kg}$ b. wt.), 3 times weekly for 2 weeks, following with i.p. injection of BPF ( $1 \mu \mathrm{gm} / 1 \mathrm{~g}$ b.wt.), once a week for 3 weeks; plus oral administration of $O$. basilicum ( $20 \mathrm{ml} / \mathrm{kg}$ b.wt.), twice a week for 6 weeks. All experimental animals were sacrificed at the end of the experiment. The serum and liver tissue were collected from the experimental groups for biochemical analysis.

\section{Biochemical assays}

Biochemical analysis in serum: For biochemical assays blood was collected and centrifuged at $3000 \mathrm{rpm}$ for 30 minutes and stored at $-20^{\circ} \mathrm{C}$. Aspartate aminotransferase (AST) and alanine aminotranferease (ALT) were determined by the kinetic method which described by Fischbach et al. and Schumann et al. [27,28], alkaline phosphatase (ALP) was measured according to the method of Belfield and Goldberg [29], albumin was determined by the colorimetric method which described by Doumas et al. [30], $\gamma$-Glutamyltransferase $(\gamma$-GT) was determined by the kinetic colorimetric method which described by Szasz [31], creatinine was determined by the method of Murray et al. [32], urea was determined by using the method of Fawcett et al. [33], uric acid was determined by the enzymatic colorimetric method which described by Barham et al. [34].

Biochemical analysis of liver tissue homogenate: Prior to dissection, perfuse liver tissue with phosphate buffered saline (PBS) solution $\mathrm{pH}=7.4$ containing $0.16 \mathrm{mg} / \mathrm{ml}$ heparin to remove any red blood cells. Then homogenize the tissue in 5-10 ml cold buffer per gram tissue. After that, Centrifuge at $4000 \mathrm{rpm}$ for $15 \mathrm{~min}$ at $4^{\circ} \mathrm{C}$. Finally, remove the supernatant for biochemical assay and store on ice (If not as saying on the same day, freeze the sample at $-80^{\circ} \mathrm{C}$ ) until used for biochemical assays.

In liver homogenate, reduced glutathione (GSH) was determined by colorimetric method described by Beutler et al. [35], Superoxide dismutase (SOD) was measured using the method described by Nishikimi et al. [36]. Catalase (CAT) was carried out according to the method of Aebi [37], Malondialdehyde (MDA) was analyzed according to the method of Ohkawa et al. [38] and nitric oxide was carried out according to the method of Montgomery et al. [39].

\section{Statistical analysis}

The results were expressed as means \pm S.D. The differences between the mean values were evaluated by one-way analysis of variance (ANOVA) followed by Dunnett's Multiple Comparison test using Graph Pad Prism 03n software. Statistical significance was set at $\mathrm{p}<0.05$. 


\section{Results}

\section{Biochemical results}

Liver function enzymes: Results in Figures 1-5 indicated that normal animals G. (1) and G. (2, 3 and 4) showed no significant difference in the activities of serum AST, ALT, ALP, $\gamma$-GT and albumin. Moreover, treatment with $\mathrm{CCl}_{4}$ for 2 weeks G.(5) showed a highly significant increase at $(\mathrm{p}<0.01)$ in the activities of serum ALT, AST, ALP and $\gamma$-GT with a highly significant decrease at $(\mathrm{p}<0.01)$ in serum albumin concentration as compared with the corresponding normal values. Activities of serum ALT, AST, ALP and $\gamma$-GT were significant decreased at $(\mathrm{p}<0.05)$ in $\mathrm{G} .(7)$ and were highly significant decreased at $(\mathrm{p}<0.01)$ in $\mathrm{G}$. (6) and G. (8). While, serum albumin

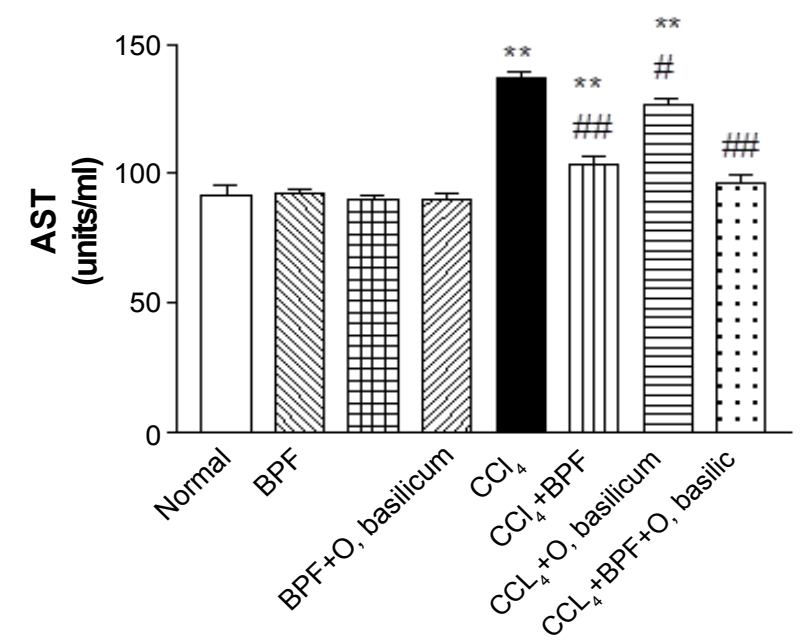

${ }^{*} p<0.05=$ significantly different from the normal.

${ }^{* *} p<0.01=$ highly significant different from the normal.

$\# \#<<0.01=$ highly significant different from the control.

$\# p<0.05=$ significantly different from the control.

Figure 1: Activities of AST in different experimental groups.

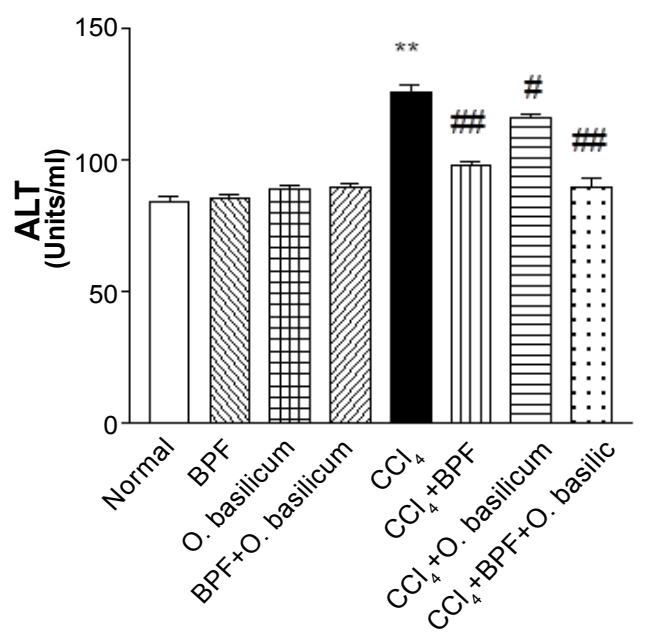

${ }^{*} p<0.05=$ significantly different from the normal.

${ }^{* *} p<0.01=$ highly significant different from the normal.

$\# p<0.05=$ significantly different from the control.

\#\# $\mathrm{p}<0.01=$ highly significant different from the.

Figure 2: Activities of ALT in different experimental groups.

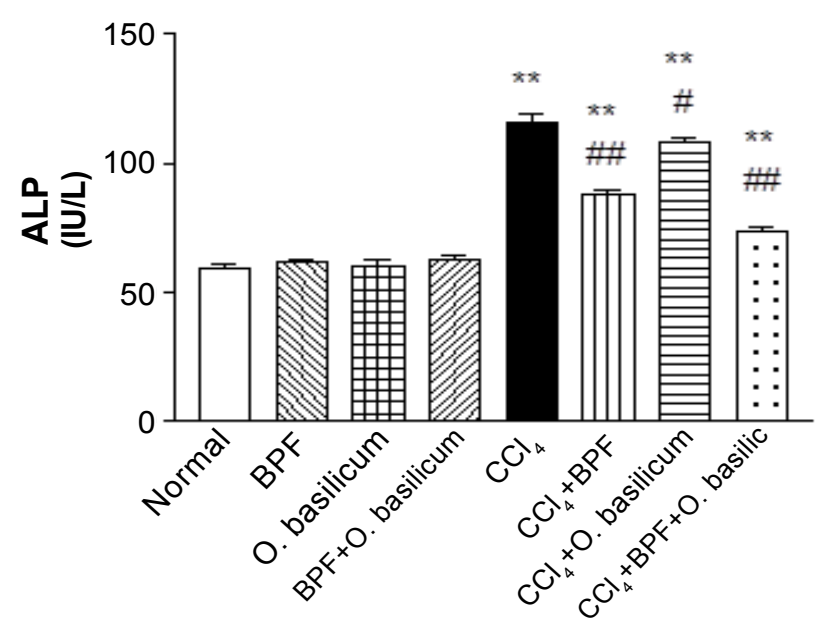

${ }^{*} p<0.05=$ significantly different from the normal.

${ }^{* *} p<0.01=$ highly significant different from the normal.

$\# p<0.05=$ significantly different from the control.

\# p $<0.01=$ highly significant different from the control.

Figure 3: Activities of ALP in different experimental groups.

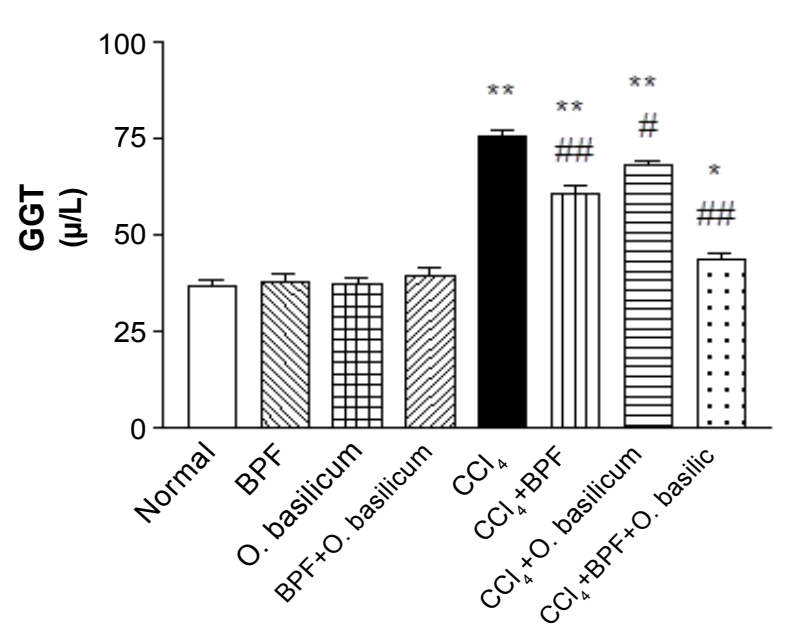

${ }^{*} p<0.05=$ significantly different from the normal.

${ }^{* *} p<0.01=$ highly significant different from the normal.

$\# p<0.05=$ significantly different from the control.

\# $p<0.01=$ highly significant different from the control.

Figure 4: Activities of GGT in different experimental groups.

concentration showed a significant increase at $(\mathrm{p}<0.05)$ in G. $(7)$ and highly significant increase at $(\mathrm{p}<0.01)$ in $\mathrm{G}$. $(6)$ and $\mathrm{G}$. (8) as compared to the control group G. (5).

Renal function: Urea and uric acid levels in serum of normal group G.(1) and G. (2, 3 and 4) showed no significant differences. While, serum creatinine showed no statistical differences in G.(2 and 3) and a significant increase in G.(4). Those findings recorded in Figures 6-8. In addition, the concentration of serum creatinine and urea in control group G. (5) were highly significantly increase, while serum uric acid concentration was highly significant decrease as compared to the normal group G.(1). Creatinine and urea levels showed a significant decrease at $(\mathrm{p}<0.05)$ in G. $(7)$ and a highly significant decrease at $(\mathrm{p}<0.01)$ in $\mathrm{G} .(6$ and 8$)$. While, uric acid level recorded a significant increase at $(\mathrm{p}<0.05)$ 


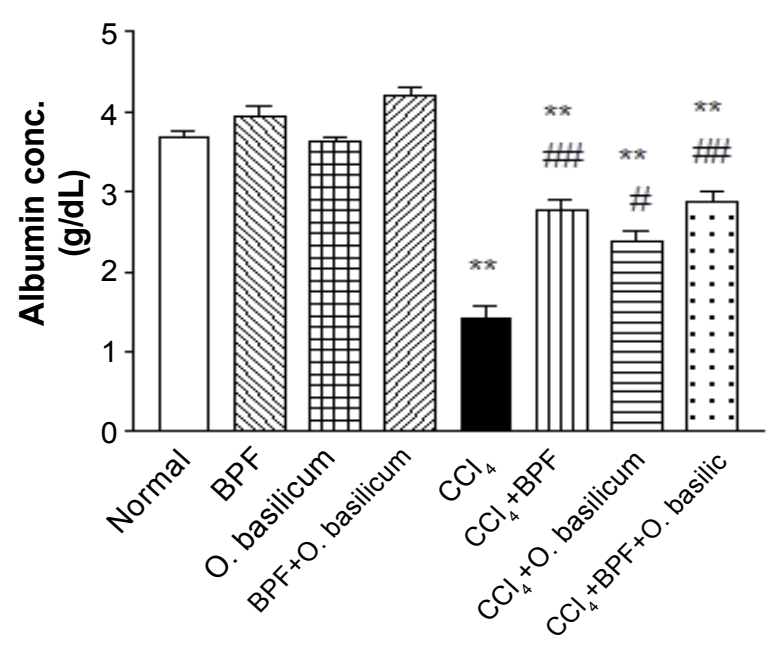

${ }^{*} p<0.05=$ significantly different from the normal.

${ }^{* *} p<0.01=$ highly significant different from the normal.

$\# p<0.05=$ significantly different from the control.

\# $\mathrm{p}<0.01=$ highly significant different from the control.

Figure 5: Activities of ALB in different experimental groups.

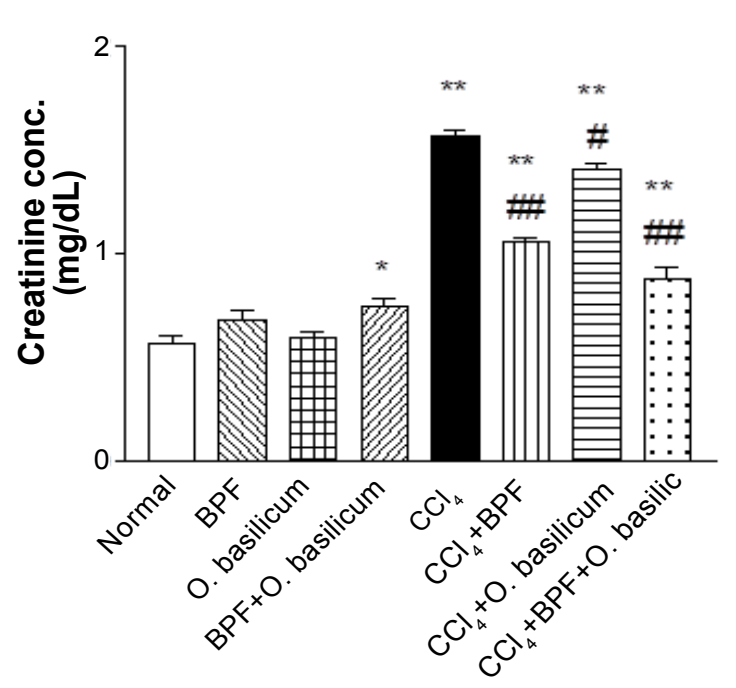

${ }^{*} p<0.05=$ significantly different from the normal.

${ }^{* *} p<0.01=$ highly significant different from the normal.

$\# p<0.05=$ significantly different from the control.

\#\# $<0.01=$ highly significant different from the control.

Figure 6: Change in Creatinine conc. in different experimental groups.

in G. (7) and a highly significant increase at $(\mathrm{p}<0.01)$ in $(\mathrm{G} .6$ and 8$)$ as compared to control group G. (5).

Liver homogenate biochemical results: Lipid Peroxidation and liver antioxidant enzyme activities results in Figures 9-13 showed no significant ( $p>0.05$ ) changes in the level of CAT, SOD, MDA and NO in G. (2, 3 and 4$)$ as compared to the normal group G. (1). Also, there was no significant difference observed between G. (1) and G. (2 and 3) in the level of liver GSH but in G. (4) GSH was highly significant increase at $(\mathrm{p}<0.01)$. Besides, $\mathrm{CCl}_{4}$ treated group G. (5) resulted in a highly significant increase in the level of liver MDA and NO, with marked reduction in GSH, CAT and SOD activities when compared with normal group. The activity of liver GSH was significantly increase in G.

(6 and 7) and highly significantly increase in G. (8) as compared to the control group G. (5). Moreover, the levels of liver SOD and CAT were highly significantly increase in G. (6 and 8) and significantly increase in G. (7) as compared to the control group G. (5). The activities of liver MDA and NO were highly significant decrease in G. (6), significant decrease in G. (7) and highly significant decrease in G. (8) as compared to the control group G. (5).

\section{Discussion}

The present study confirmed the beneficial effect of bradykinin

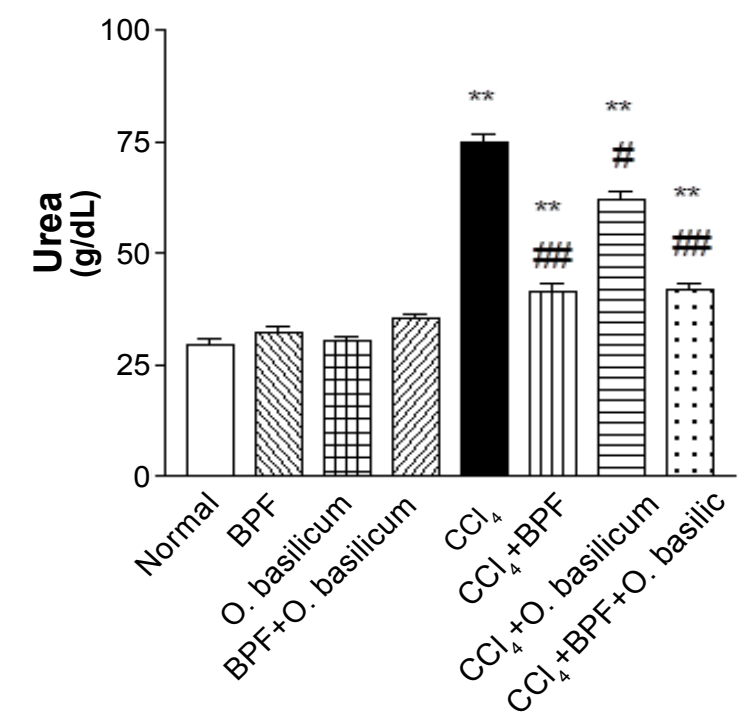

${ }^{*} \mathrm{p}<0.05=$ significantly different from the normal.

${ }^{* *} p<0.01=$ highly significant different from the normal. $\# p<0.05=$ significantly different from the control.

$\#$ \# $<0.01=$ highly significant different from the control.

Figure 7: Change in Urea in different experimental groups.

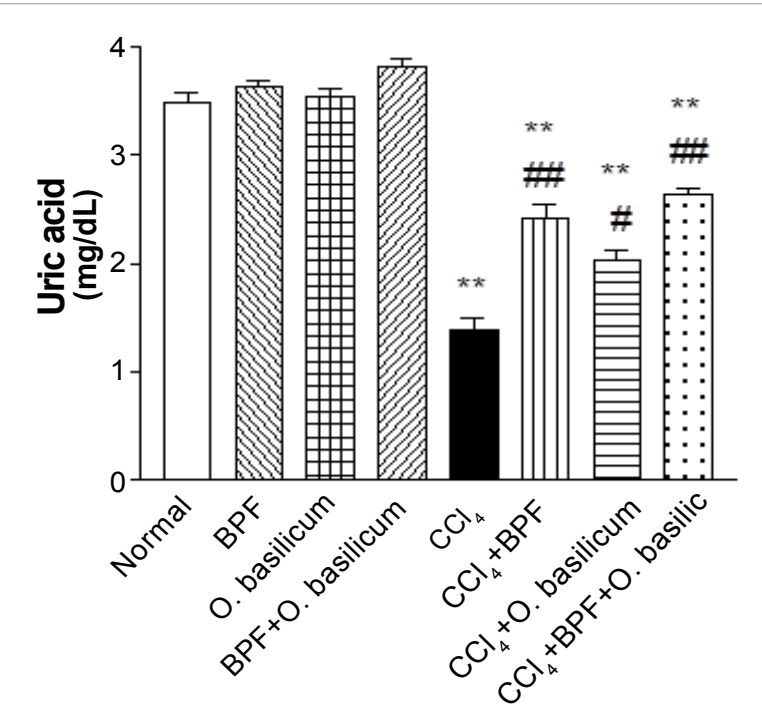

${ }^{*} p<0.05=$ significantly different from the normal.

${ }^{* *} p<0.01=$ highly significant different from the normal.

$\# \mathrm{p}<0.05=$ significantly different from the control.

$\# \#$ < $0.01=$ highly significant different from the control.

Figure 8: Change in Uric acid in different experimental groups. 


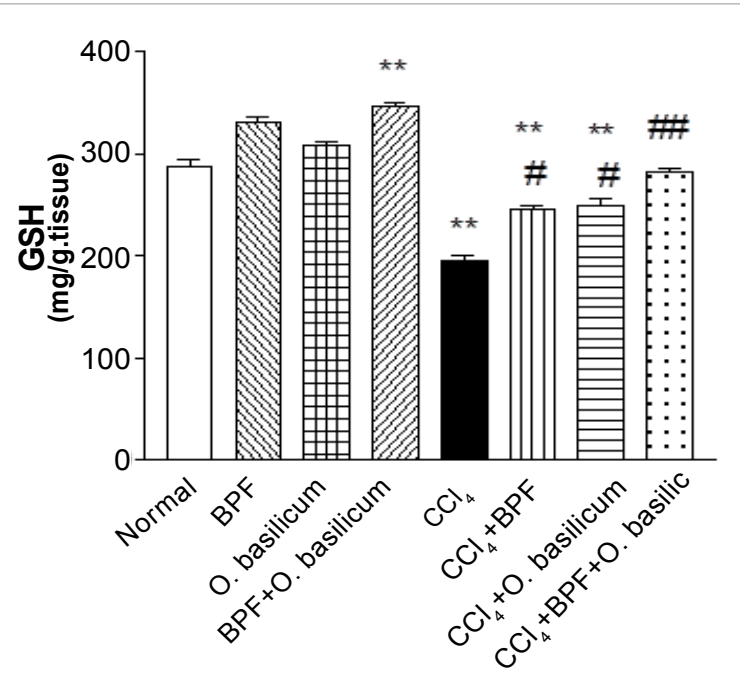

${ }^{*} \mathrm{p}<0.05=$ significantly different from the normal.

${ }^{* *} p<0.01=$ highly significant different from the normal. $\# p<0.05=$ significantly different from the control.

\# $\mathrm{p}<0.01=$ highly significant different from the control.

Figure 9: Hepatic GSH in different experimental groups.

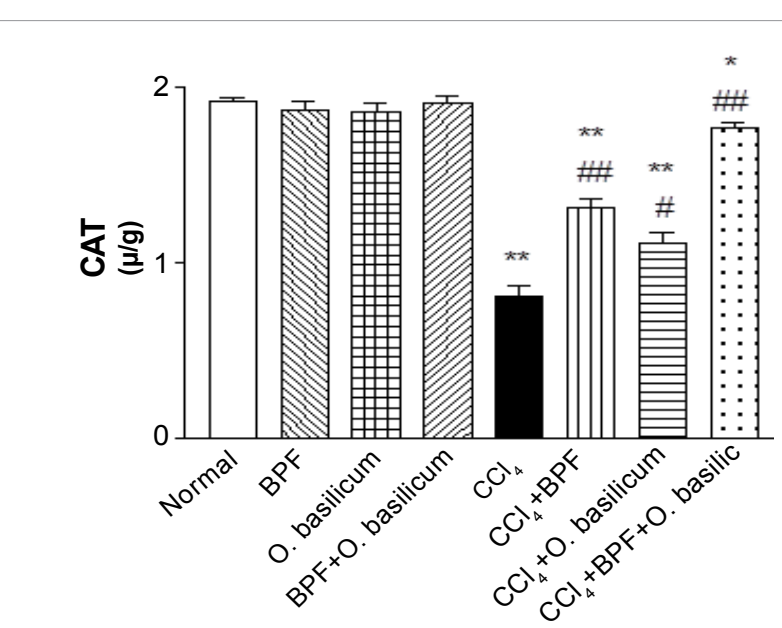

${ }^{*} p<0.05=$ significantly different from the normal.

${ }^{* \star} p<0.01=$ highly significant different from the normal.

$\# p<0.05=$ significantly different from the control.

$\# \#$ p $<0.01=$ highly significant different from the control.

Figure 10: Hepatic CAT in different experimental groups.

potentiating factor (BPF) and basil (O. basilicum) in the prevention of liver and kidney toxicity produced by $\mathrm{CCl}_{4}$. It also, showed a comparison between the treatment of liver and kidney toxicity by BPF or by basil, as a drug already used for the treatment of liver and kidney toxicity. Results obtained in the present work indicated that carbon tetrachloride $\left(\mathrm{CCl}_{4}\right)$ induced biochemical alterations in albino rats.

The present study revealed that, injection of $\mathrm{CCl}_{4}$ induced a highly significant increase in serum ALT, AST, ALP and $\gamma$-GT levels while albumin stated a highly significant decrease. The status of these marker enzymes are sensitive indices of hepatocellular necrosis as cell damage results in the leakage of these enzymes into the systemic circulation [40]. These elevations in the serum liver marker enzymes could be attributed to the free radicals which caused structural integrity damage of the liver cell membrane and hence a leakage of the cellular enzymes in to the blood [41]. The reduction in serum albumin is due to the hepatic injury which caused by $\mathrm{CCl}_{4}[42]$. Highly Significant reduction in ALT, AST, ALP and $\gamma$-GT levels and highly significant increase in serum albumin of serum of BPF treated rats was recorded in the present study. This effect may be attributed to the prevention of the leakage of intracellular enzymes by its membrane stabilizing activity [43]. In addition, treatment with O.basilicum remitted the decreased serum albumin and the increase in serum ALT, AST, ALP and $\gamma$-GT levels. The mechanism of action may be due to its free radical scavenging (antioxidant) activity [44].

Elevated creatinine, urea and uric acid levels were observed in rat's injected i.p. with $\mathrm{CCl}$. These increments could be considered as impairment in renal functions. The increase in serum creatinine

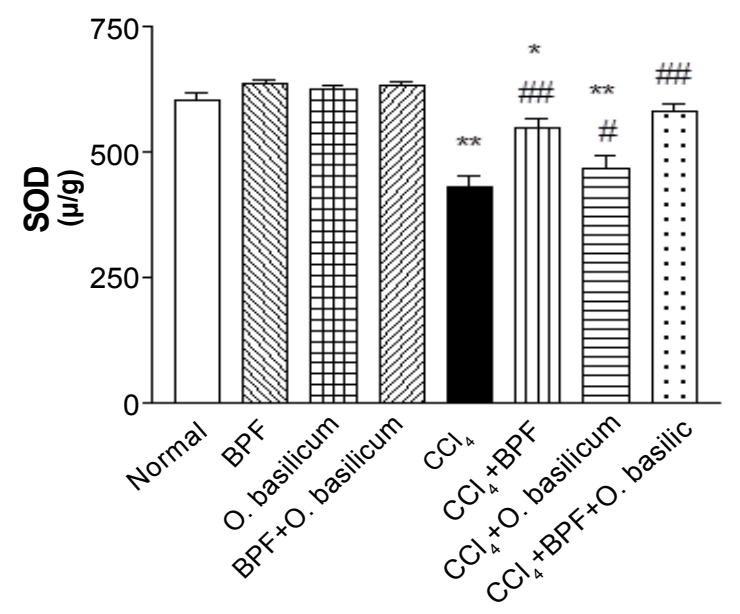

${ }^{*} p<0.05=$ significantly different from the normal.

${ }^{* *} p<0.01=$ highly significant different from the normal. $\# p<0.05=$ significantly different from the control. \# p <0.01=highly significant different from the control.

Figure 11: Hepatic SOD in different experimental groups.

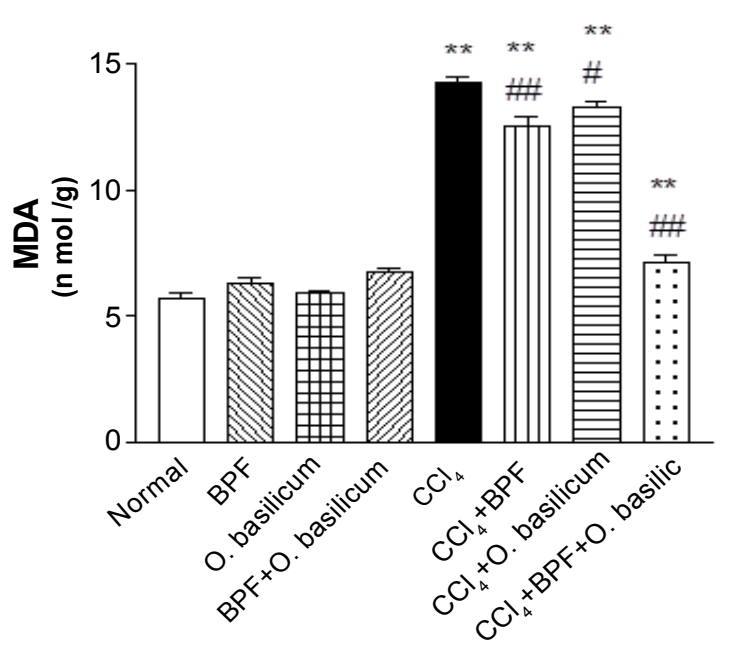

${ }^{*} p<0.05=$ significantly different from the normal.

${ }^{* *} p<0.01=$ highly significant different from the normal. $\# p<0.05=$ significantly different from the control. \# p $<0.01=$ highly significant different from the control.

Figure 12: Hepatic MDA in different experimental groups. 


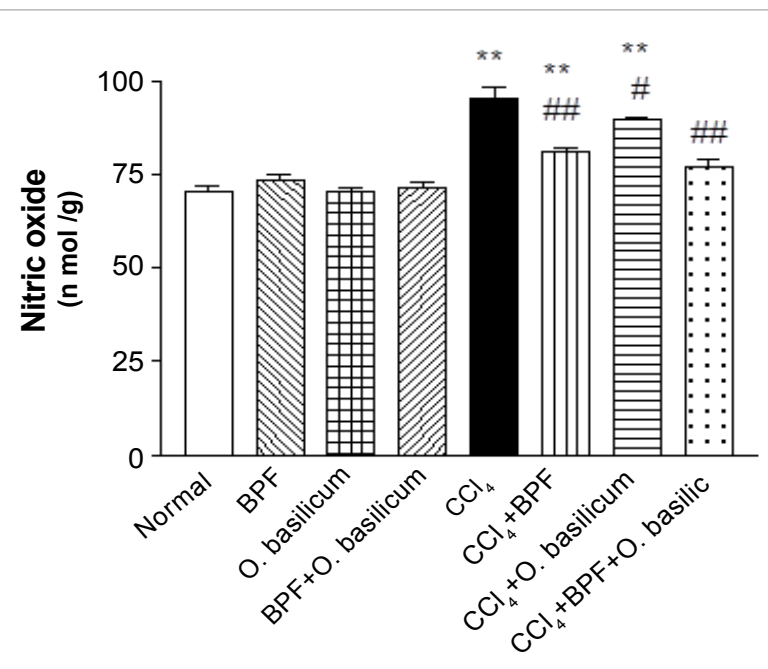

${ }^{*} p<0.05=$ significantly different from the normal.

${ }^{* *} p<0.01=$ highly significant different from the normal. $\# p<0.05=$ significantly different from the control.

\# $p<0.01=$ highly significant different from the control.

Figure 13: Hepatic Nitric oxide in different experimental groups.

and urea levels may indicate a reduction in the glomerular filtration rate (GFR) as a result of acute renal dysfunction [45]. The reduction in serum uric acid level in the present study may be attributed to the increased utilization of uric acid against increased production of the free radicals since it has a capable especially of reacting with free radicals [46]. Treatment with BPF (G. 6) and basil (G. 7) ameliorated the elevation of kidney functions parameters. BPF induced prostaglandin biosynthesis which as a cytoprotective regulatory substance may trigger enhanced glomerular filtration in guinea pigs [47]. The ameliorative effect of $O$. basilicum against renal toxicity may be attributed to the antioxidant activity of one or more of its flavonoids which have been shown to possess various biological properties related to antioxidant mechanisms [48].

The present study showed that i.p. injection with $\mathrm{CCl}_{4}$ produced marked oxidative impact as evidenced by a highly significant increase in MDA and NO levels in liver tissue homogenate. This increase may be due to excessive formation of free radicals and activation of lipid peroxidation of cell damage in liver of rats treated with $\mathrm{CCl}_{4}[49,50]$. Furthermore, it was reported that a high level of nitric oxide (NO) is associated with $\mathrm{CCl}_{4}$-induced acute liver injury [51]. NO can protect hepatic cells against oxidative damage and lipid peroxidation caused by carbon tetrachloride and $\mathrm{H}_{2} \mathrm{O}_{2}$-mediated oxidative stress.

The marked elevation of MDA and NO levels associated with a highly significant decrease in the activities of hepatic SOD, CAT and $\mathrm{GSH}$ were recorded after i.p. injection of $\mathrm{CCl}_{4}$. It has been reported that exposure to $\mathrm{CCl}_{4}$ induces oxidative stress in rats [52]. Oxidative stress is a state of redox imbalance caused by increased reactive oxygen species (ROS) generation and decreased antioxidant capacity. This process is the main and primary step in $\mathrm{CCl}_{4}$ toxicity contributing to both onset and progression of fibrosis [53]. Hepatotoxicity produced by $\mathrm{CCl}_{4}$ seems to be mediated by reactive metabolite trichloromethyl free radical $\left(\mathrm{CCl}_{3}\right)$ formed by the hemolytic cleavage of $\mathrm{CCl}_{4}$ or even by more reactive species trichloromethylperoxy free radical $\left(\mathrm{Cl}_{3} \mathrm{COO}\right)$ formed by the reaction of $\mathrm{CCl}_{3}$ with $\mathrm{O}_{2}$. The reactive trichloromethyl radical binds covalently to the macro-molecules and induces peroxidative degradation of membrane lipids of endoplasmic reticulum rich in polyunsaturated fatty acids. This peroxidative degradation of membrane lipids leads to the formation of lipid peroxides which probably causes damage to cell membrane of hepatocytes and resulted in centrilobular necrosis [54].

In rats treated with BPF, hepatic SOD, Catalase activities and GSH levels were highly significant increased while MDA and NO levels were highly significant decreased. This result was in accordance with who reported that BPF showed an improvement in the levels of antioxidant enzymes (GSH, CAT and SOD) in liver. This improvement may be due to the antioxidant effect of BPF. Furthermore, the antioxidant activity of BPF may be attributed to the scavenging of $\mathrm{CCl} 3$ - radical. Furthermore, the decreased level of MDA, observed after bradykinin administration, may point to a reduction in free radicals production. $\mathrm{BPF}$ also can regulate the production of nitric oxide by activation of bradykinin while, bradykinin stimulates nitric oxide [55]. The treatment with $O$. basilicum induced significant increase in GSH, Catalase and SOD activities and significant decrease in MDA and NO levels in liver tissue of treated rats. This may be attributed to the presence of numerous compounds with high antioxidant activities that scavenge the produced superoxide anion and hydroxyl radicals [56]. Rats treated with BPF plus O.basilicum (G. 8) showed marked improvements in all biochemical parameters. This may be attributed to the antioxidant effect and free radical scavenging properties of the both treatments.

It could be concluded that treatment with the extract from the scorpion venom Buthus occitanus (BPF) is more effective than those of extract from the plant (O. basilicum) against the toxicity of liver and kidney-induced by carbon tetrachloride $\left(\mathrm{CCl}_{4}\right)$ in albino rats. In addition, the hepato-ameliorating and antioxidant effects of two extracts were found to be better than those of extract of BPF or $O$. basilicum independently.

\section{References}

1. Bogers M, Appelman LM, Feron VJ, Beems RB, Notten WR (1987) Effects of the exposure profile on the inhalation toxicity of carbon tetrachloride in male rats. J Appl Toxicol 7: 185-191.

2. Salman MMA, Elshater AA, Fayad AS (2011) Effect of bradykinin potentiating factor isolated from scorpion venom (Buthus occitanus) on liver injury in Guinea pigs induced by carbon tetrachloride (CCI4). J Ger Soc Zool 63: 297-311.

3. Preis S, Kallas J (2004) Gas-phase degradation of $\mathrm{CCl} 4, \mathrm{CHCl} 3$ and $\mathrm{CH} 2 \mathrm{Cl} 2$ over metallic Fe. Environ Chem Lett 2: 9-13

4. Das RK, Hossain SU, Bhattacharya S (2007) Protective effect of diphenylmethyl selenocyanate against CCl4-induced hepatic injury. J Appl Toxicol 27: 527-537.

5. Lin WC, Wu YW, Shih CC (2005) Aqueous extract of Anoectochilus formosanus attenuate hepatic fibrosis induced by carbon tetrachloride in rats. Phytomedicine 12: 453-460.

6. Wang CY, Ma FL, Liu JT, Tian JW, Fu FH (2007) Protective effect of salvianic acid a on acute liver injury induced by carbon tetrachloride in rats. Biol Pharm Bull 30: 44-47.

7. Manibusan MK, Odin M, Eastmond DA (2007) Postulated carbon tetrachloride mode of action: a review. J Environ Sci Health C Environ Carcinog Ecotoxicol Rev 25: 185-209.

8. Basu L (2003) Carbon tetrachloride-induced lipid peroxidation: eicosanoid formation and their regulation by antioxidant nutrients. Toxicol 189: 113-127.

9. Sies $H$ (1991) Role of reactive oxygen species in biological processes. Klin Wochenschr 69: 965-968.

10. Sakr SA, El-Abd SF, Osman M, Kandil AM, Helmy MS (2011) Ameliorative Effect of Aqueous Leave Extract of Ocimum basilicum on CCl4-Induced Hepatotoxicity and Apoptosis in Albino Rats. J Am Sci 7: 116-27.

11. Kumar G, Banu GS, Pandian MR (2005) Evaluation of the antioxidant activity of Trianthema portulacastrum L. Ind J Pharmacol 37: 331-333.

12. Khan MR, Ahmed D (2009) Protective effects of Digera muricata (L.) Mart. on 
Citation: Salman MMA, Kasem NRA, Saleh NHM (2016) Comparative Effects of Scorpion Venom and Aqueous Basil (Ocimum basilicum) Leaves Extracts on Ccl4-induced Toxicity in Albino Rats. J Liver 5: 201 doi: 10.4172/2167-0889.1000201

testis against oxidative stress of carbon tetrachloride in rat. Food Chem Toxicol 47: 1393-1399.

13. Khan MR, Rizvi W, Khan GN, Khan RA, Shaheen S (2009) Carbon tetrachloride-induced nephrotoxicity in rats: protective role of Digera muricata. J Ethnopharmacol 122: 91-99.

14. Nassar AY, Soliman, FM (1989) Fractions with bradykinin potentiating activity composed of 14-16 amino acid residues were isolated from venoms of the Egyptian scorpions and snakes. Assiut Medical J 13: 39-44.

15. Abd-El-Rahim SA, Abu-Amra E (1992) Effect of a bradykinin potentiating fraction from the venom of the Egyptian scorpion, Buthus occitanus on the testis of mature mice. Proc Zool Soc AR Egypt 23: 115-122.

16. Abu-Amra E, Abd-El-Rahim SA (1992a) Activation of some enzymes activities of the plasma and liver of white rat by a venom fraction isolated from scorpion and snake. Proc Zoo Soc ARE 32: 123-128.

17. Abu-Amra E, Abd-El-Rahim SA (1992b) Effect of factors isolated from venoms of Egyptian snakes in plasma cholesterol, creatine kinase and alkaline phosphatase. J Egypt Ger Soc Zool 9: 75-89.

18. Meki A, Mansuelle $P$, Laraba-Djebari $F$, Oughideni $R$, Rochat $H$, et al. (2000) KTX3, the kaliotoxin from Buthus occitanus tunetanus scorpion venom: one of an extensive family of peptidyl ligands of potassium channels. Toxicon 38 : 105-111.

19. Salman MMA (1995) Effect of a bradykinin potentiating factor isolated from scorpion venom, Buthus occitanus on burnt skin of Guinea pig in comparison with other drugs. M. Sc. Thesis, Faculty of Science, Ain Shams University.

20. Kandasamy CS, Shimna TP, Mohammed BE, Arul RP, Gopal V, et al. (2010) Anti-hepatotoxic activity of polyherbal formulation in carbon tetrachloride induced toxicity in rats. RJPBCS 1: 342-346.

21. Bass NM (1999) Is there any use for nontraditional or alternative therapies in patients with chronic liver disease? Curr Gastroenterol Rep 1: 50-56.

22. Yacout GA, Elguindy NM, El Azab EF (2012) Hepatoprotective effect of basi (Ocimum basilicum L.) on CCl4-induced liver fibrosis in rats. Afr J Biotechnol 11: $15702-15711$.

23. Dasguptazz T, Rao AR, Yadava PK (2004) Chemo-modulatory efficacy of basil leaf (Ocimum basilicum) on drug metabolizing and antioxidant enzymes, and on carcinogen-induced skin and fore stomach papillomagenesis. Phytomedicine 11: $139-151$.

24. Bozin B, Mimica-Dukic N, Simin N, Anackov G (2006) Characterization of the volatile composition of essential oils of some lamiaceae spices and the antimicrobial and antioxidant activities of the entire oils. J Agric Food Chem 54: $1822-1828$

25. Ferreira SH, Rocha e Silva M (1965) Potentiation of bradykinin and eledoisin by BPF (bradykinin potentiating factor) from Bothrops jararaca venom. Experientia 21: 347-349.

26. Offiah VN, Chikwendu UA (1999) Antidiarrhoeal effects of Ocimum gratissimum leaf extract in experimental animals. J Ethnopharmacol 68: 327-330.

27. Fischbach F, Zawta B (1992) Age-dependent reference limits of severa enzymes in plasma at different measurement temperatures. Klin Lab 38: 555 561.

28. Schumann G, Klauke $R$ (2003) New IFCC reference procedures for the determination of catalytic activity concentrations of five enzymes in serum: preliminary upper reference limits obtained in hospitalized subjects. Clin Chim Acta 327: 69-79.

29. Belfield A, Goldberg DM (1971) Revised assay for serum phenyl phosphatase activity using 4-amino-antipyrine. Enzyme 12: 561-573.

30. Doumas BT, Watson WA, Biggs HG (1971) Albumin standards and the measurement of serum albumin with bromocresol green. Clin Chim Acta 31 87-96.

31. Szasz G (1969) A kinetic photometric method for serum gamma-glutamyl transpeptidase. Clin Chem 15: 124-136.

32. Murray RL (1984) Creatinine In: Clinical Chemistry; Theory, Analysis and Correlation, Kaplan LA and Pesce AJ (Eds) CV Mosby Co., St. Louis.

33. Fawcett JK, Scott JE (1960) A rapid and precise method for the determination of urea. J Clin Pathol 13: 156-159.
34. Barham D, Trinder P (1972) An improved colour reagent for the determination of blood glucose by the oxidase system. Analyst $97: 142-145$

35. Beutler E, Duron O, Kelly BM (1963) Improved method for the determination of blood glutathione. J Lab Clin Med 61: 882-888.

36. Nishikimi M, Appaji N, Yagi K (1972) The occurrence of superoxide anion in the reaction of reduced phenazine methosulfate and molecular oxygen. Biochem Biophys Res Commun 46: 849-854.

37. Aebi $H$ (1984) Catalase in vitro. Methods Enzymol 105: 121-126.

38. Ohkawa H, Ohishi N, Yagi K (1979) Assay for lipid peroxides. In: Animal tissue by thiobarbituric acid reaction. Anal Biochem 95: 351-358.

39. Montgomery HAC, Dymock JF (1961) Colorimetric method for determination of nitrite in water. Analyst 86: 411-422.

40. Hyun PS, Kannampalli P, Hee ChM, Kyong-Cheol K, Hae-Jun P (2010) Hesperidin and Curdlan treatment ameliorates $\hat{i}^{3}$-radiation induced cellular damage and oxidative stress in the liver of Sprague Dawley rats 1: 165-177.

41. Patel BA, Patel JD, Raval BP, Gandhi TR (2010) The Protective Activity of Saccharum officianarum Against $\mathrm{CCl} 4$ Induced Hepatotoxicity in Rats. Int $\mathrm{J}$ Pharm Res 2: 5-8.

42. Etuk EU, Agaie BM, Ladan MJ, Garba I (2009) The modulatory effect of Cochlospermum tinctorium a rich aqueous root extract on liver damage induced by carbon tetrachloride in rats. AJ Pharmacy Pharm 3: 151-157.

43. Green M, Pragada RR, Ethadi S, Rajanna B (2013) Comparative study on some selected species of Ocimum genus on free radical scavenging activity and hepatoprotective activity against $\mathrm{CCl} 4$ induced intoxication in rats. AJMB 3: 183-186.

44. Gavin JB (1995) Assessment of renal function. The Md GR J 23: 102-105

45. Rahmat AA, Dar FA, Choudhary IM (2014) Protection of CCl4-Induced Liver and Kidney Damage by Phenolic Compounds in Leaf Extracts of Cnestis ferruginea (de Candolle). Pharmacognosy Res Jan-Mar 6: 19-28.

46. Hasegawa T, Kuroda M (1989) A new role of uric acid as antioxidant in human plasma. Rinsho Byori 37: 1020-1027.

47. Fabbrini E, Serafini M, Baric IC, Hazen SL, Klein S (2014) Effect of Plasma Uric Acid on Antioxidant Capacity, Oxidative Stress, and Insulin Sensitivity in Obese Subjects. Diabetes 63: 976-981.

48. El-Saadani MA (2004) A scorpion venom peptide fraction induced prostaglandin biosynthesis in Guinea pig kidneys: incorporation of 14C-linoleic acid. J Biochem 135: 109-116.

49. Sakr SA, Al-Amoudi WM (2012) Effect of leave extract of Ocimum basilicum on deltamethrin induced nephrotoxicity and oxidative stress in albino rats. J App Pharmaceut Sci 2: 22-27.

50. Fraga CG, Leibovitz BE, Tappel AL (1987) Halogenated compounds as inducers of lipid peroxidation in tissue slices. Free Radic Biol Med 3: 119-123.

51. Mahmoud SM, Abdel Moneim AE (2013) The Protective Effect of Pomegranate (Punica granatum) Juice against Carbon Tetrachloride-Induced Oxidative Stress in Brain Tissue of Adult Male Albino Rats. Life Sci J 10: 151-158.

52. Tipoe GL, Leung TM, Liong $\mathrm{E}$, So $\mathrm{H}$, Leung KM, et al. (2006) Inhibitors of Inducible Nitric Oxide (No) Synthase Are More Effective Than An No Donor In Reducing Carbon Tetrachloride-Induced Acute Liver Injury. Histol Histopatho 21: $1157-1165$.

53. Sharama R, Mathur S, Shukla S (1995) Hepatoprotective action of propriety herbal preparation against carbon tetrachloride intoxication. Indian Drugs 32 120-124.

54. Boll M, Weber LWD, Becker E, Stampl A (2001) Mechanism of carbon tetrachloride-induced hepatotoxicity. Hepatocellular damage by reactive carbon tetrachloride metabolites. Zeitschrit fur Naturforschung CJ of Biosciences 56: 649-659.

55. Cabre M, Camps J, Paternain JL, Ferre N, Joven J (2000) Time-course of changes in hepatic lipid peroxidation and glutathione metabolism in rats with carbon tetrachloride induced cirrhosis. Clin Exp Pharmacol Physiol 27: 694699

56. Valdés G, Corthorn J (2011) Review: The angiogenic and vasodilatory uteroplacental network. Placenta 32 Suppl 2: S170-175. 